\title{
The New Censorship: Anti-sexuality Groups and Library Freedom 1
}

A sudden loss of library database access by public school students in Utah; a Missouri bill proposing the jailing of librarians; a rise in demands for internet filtering; a wave of states declaring pornography a public health crisis; the attempted implementation of a nationwide internet filter in the United Kingdom and Canada. While each of these censorship attempts may seem sporadic and the challengers disparate or unconnected, a deeper examination reveals that there are similarities in the histories, concerns, and tactics between and among the various actors in these stories. Over the past decade, a number of anti-sexuality groups funded by similar groups or individuals have coalesced into an international movement directly at odds with intellectual freedom and privacyand have repeatedly targeted public libraries as sites of freedom.

Over the same span of time, libraries have grown increasingly reluctant to be battlegrounds upon which cultural wars play out. As a result, librarians 'on the front lines' are facing new types of censorship and campaigns for which library literature does not fully prepare them. Although the American Library Association's (ALA) Intellectual Freedom Manual offers a number of strategies (in II.2: Censorship, Challenged Resources, and Internet Filtering) for dealing with individuals or locallyorganized groups, it does not offer recommendations on occurrences that fall outside of those types. Each of the events in the previous paragraph involve individuals typically only looselyaffiliated with or inspired by internet-savvy nationally-run anti-sexuality groups. These groups, such as the National Center on Sexual Exploitation (NCOSE) or Fight The New Drug (FTND), follow a different strategy than the ones identified in the ALA manual. Rather than organize on a local level or fund local chapters of a national organization, they instead offer blogging platforms or guides aimed helping local activists take initiative on their own. If an individual is successful in making the news, the larger group will often attempt to capitalize on a local controversy and make it a national one. Finally, many anti-sexuality groups have adopted rhetorical tactics from conservative climate change denialists such as 'well poisoning' and spreading FUD (fear, uncertainty, doubt).2

1 The author is indebted to the helpful feedback, editing and criticism of Jessamyn West, Rob Sarwark, Amie Gagnon, Melissa Norr, and their partner, Shannon Caitlin Devlin. Thank each of you for your feedback.

2 A term associated with sales, marketing and public relations that refers to the spreading of negative or false information to influence listeners. See also Raymond, Eric S. "FUD." The Jargon File 4.4.7,

http://www.catb.org/ esr/jargon/html/F/FUD.html. Accessed 23 Mar. 2019. 
The purpose of this article is to document the shared histories, concerns, and strategies of these groups, with the aim of 'inoculating' the well, informing the library community as a whole, and supplying individual libraries with helpful information as they prepare new contingency plans. First, it will detail the histories and motivations of the three main branches of this movement. Then, narrowing focus, it will turn to the multiyear conflict between NCOSE and ALA. Finally, it will conclude by reviewing some effective guidelines and strategies adopted by local librarians.

\section{Background}

Since 2016, 16 states have passed or proposed bills declaring pornography a "Public Health Crisis," and more are likely to follow (Arnold 2017; Knibbs 2015; Gayle 2016). Additionally, the 2018 signing and 2019 implementation of the federal law known as Stop Enabling Sex Traffickers Act/ Fight Online Sex Trafficking Act, although aimed at sex-trafficking, has primarily had negative effects on intellectual freedom online (Watson 2019a).3 Given the increased funding to these groups under the Trump administration, as well as an aggressive lobbying campaign by conservative groups, these incidents will likely continue rising in coming years (Coaston 2019). Focusing on libraries specifically, a two-decade review of news articles, statistics, and reports undertaken for this article reveals an uptick in challenges and campaigns by specific anti-sexuality organizations and affiliated members ("Censorship Dateline," opera omnia; American Library Association 2013; Tobar 2013; Flood 2015).4 An additional trend, possibly connected, is the worrying rise in selfcensorship by librarians in the past few years (Holley 2014; Dawkins 2018; Jacobson 2016; Baillie 2017; Jamison 2018; Rickman 2010).

3 SESTA/FOSTA is the combined name of the Stop Enabling Sex Traffickers Act (SESTA) and Allow States and Victims to Fight Online Sex Trafficking Act (FOSTA) laws.

4 Every issue of "Censorship Dateline" in Newsletter on Intellectual Freedom and Journal of Intellectual Freedom and Privacy, a publication of ALA's Office Of Intellectual Freedom from 1998 and to 2018 was consulted and counted, alongside ALA-OIF's Annual Reports on Censorship

(http://www.ala.org/advocacy/bbooks/frequentlychallengedbooks/statistics), as well as analyses of newspaper databases and the reports of antipornography organizations discussed below.

Statistics from American Library Association, Office of Intellectual Freedom. "Number of Challenges by Reasons, Initiator, \& Institution, 1990-99." Banned and Challenged Books, American Library Association, 6 Sept. 2013,

http://www.ala.org/advocacy/bbooks/frequentlychallengedbooks/statistics/1990-99 and American Library Association, Office of Intellectual Freedom. "Number of Challenges by Reasons, Initiator, \& Institution, 2000-09." Banned and Challenged Books, American Library Association, 6 Sept. 2013,

http://www.ala.org/advocacy/bbooks/frequentlychallengedbooks/statistics/2000-09 show a significant rise in Challenges by "Other Initiator," "Other Business” and in Schools and School Libraries specifically, which NCOSE and others suggest as particular targets. Furthermore, as all of these groups claim to be non-religious (even though they actually are), there is a corresponding fall in religious objections and clergy initiators. It is important to remember that the ALA estimates that these numbers only cover $10 \%$ of all challenges. 
Furthermore, as academic publishers monopolize and shrink in number, it becomes easier for a single individual's action to have major impacts on information access. This was demonstrated last year in Utah, when Nicholeen Peck, a "politically active parenting blogger" (Roberts, Jones, and Pflaum 2018) and self-described "worldwide phenomenon and leader" (Peck 2018) filed a complaint about lesbian, gay, bisexual, trans*, and queer (LGBTQ) material found on the database of academic resource provider EBSCO. The news was quickly nationalized through conservative media, and resulted in nearly all public schools in Utah losing access to EBSCO databases for a month (Watson 2019b; Mower 2018; LaRue 2018; Murray 2017).

Aside from an individual's political stance on matters of sexual representation, free sexual expression is often cited as the 'canary in the coal mine' for other types of civil and intellectual freedoms (Smith 2018; Jackman 2018), with some arguing that a legal system that "ostensibly exists to censor pornography [will also initiate] controls on other expression" (Barnett 2016, Chapter 2). ALA's own research demonstrates the accuracy of that concern: antipornography filters also filter sexual health and LGBTQ+ content (Barack 2016).

\section{Tripartite Histories}

The new anti-sexuality movement can be loosely categorized into three main groups, which will be discussed in order: antipornography feminists, internet activist 'Fapstronauts,' and religious morality groups. There is significant overlap and interconnection between these three branches. As discussed in further detail below, they share board members, funding, pseudoscientific literature recommendations, affiliate book links, cosigned letters, podcasts, videos, and interviews. Their shared assertion is that uncontrolled pornography and sexuality present a great danger to modern society.

Although feminist antipornography activists have not targeted libraries as much as religious organizations have, they play a critical role in the movement as a whole. The most active figure in the movement is the self-identified 'radical' feminist Gail Dines, author of two books on pornography (Pornography: The Production and Consumption of Inequality and Pornland: How Porn Has Hijacked Our Sexuality), and founder of Culture Reframed (previously known as Stop Porn Culture). Culture Reframed (CR), like many of the groups mentioned here, frequently mentions that it is non-religious-but it has accepted funding from religious groups, appears alongside them at events, takes part in group interviews, and posts on each other's blogs (Boulton 2015, 81-84; 
Jewish Community Foundation Of The Jewish Federation Council Of Greater Los Angeles 2017, 220; CAF America 2017, 583; The Simms/Mann Family Foundation 2017, 40).

Antipornography feminism, as historians Whitney Strub and Carolyn Bronstein discuss separately (Bronstein 2011; Strub 2011) and together (Bronstein and Strub 2016), developed as a distinct movement in the 1970s and 1980s, inspired by the work of second-wave feminists Gloria Steinem, Catharine McKinnon, and Andrea Dworkin. The movement reacted against a "broad range of sexually violent and sexist mainstream media" (Bronstein 2011,11) and were "will[ing] to call on the powers of state [censorship] in the name of suppression" (Strub 2011, 214). Most notably, this took the form of the Anti-Pornography Civil Rights Ordinance. The Ordinance "held that pornography itself was a form of violence against women, the image of sex and/or sexual violence was every bit as real and as harmful as an act of rape, battering, or incest" (Bronstein 2011, 19), and as pornography "injured all women" (ibid.), it allowed them to seek damages via lawsuits. For obvious reasons, the New Right, which also traces its history to these decades, found common cause with leaders in the antipornography feminist movement. Although this ordinance was ruled unconstitutional by the U.S. Supreme Court in 1986, it has recently enjoyed a second life; some states (like Minnesota) have drawn upon its language in anti-revenge pornography statues (State of Minnesota 2019), while others (like Utah) have more or less rewritten it for the use of minors who 'became' pornography 'addicts' (SB0185: Cause of Action for Minors Injured by Pornography 2017).

The Utah law is especially remarkable, as it is tangible evidence of the continued collaboration between the two groups. Dines and Culture Reframed have also made common cause with evangelical groups lobbying state legislatures to declare pornography a public health crisis. As already noted, a third of US state legislatures have agreed, passing resolutions with near-verbatim language. This alliance was internationally successful as well, persuading the United Kingdom to mandate a nationwide pornographic filter, which, unsurprisingly, also ended up disproportionately censoring LGBTQ+ resources (Boulton 2015, 83). That same year, Dines and Julia Beazley of the Evangelical Fellowship of Canada testified before the Canadian Parliament in favor of a similar law (ibid). This radical feminist / conservative Christianist anti-sexuality alliance has also taken credit for the suppression of sexual representation and LGBTQ+ material on Tumblr, and called for the use of filtering software on "all platforms and public venues - such as Instagram and YouTube, as well as restaurants, libraries [and] college campuses," (Boulton 2015, 83-84; Culture Reframed 2018, emphasis in the original). 
Another connection is observable in a recent bill proposed in Missouri that called for the enactment of "parental library review boards" that "would evaluate whether any library materials constitute 'age-inappropriate sexual material'” (Baker 2020, 2-3). Any public library who allowed a child to access sexuality material-even accidentally—"would have their funding stripped, and librarians who refuse to comply with the act can be fined and imprisoned for up to one year"(PEN America 2020; Strauss 2020; Seipel 2020; Flood 2020). Dines' books are frequently cited and lauded in evangelical circles, and used in arguments that unfettered access to pornography is the root cause of rape, child abuse, destruction of innocence, 'homosexuality,' and 'transgenderism' (Metaxis 2016; Chu 2018; Liam 2017).5

Dines' work is a major influence on the second branch of the anti-sexuality movement, which I will refer to here as 'NoFap,' after the largest and most visible group. The NoFap movement is largely made up of younger men (in their 20s-30s) who congregate on internet forums like Reddit's 'NoFap' or the community-founded website www.NoFap.com. The movement, which is named after a rather unfortunate onomatopoeia for male masturbation, has over half a million (551,300 in January of 2020; "r/NoFap” 2011) 'Fapstronauts' who seek to "abstain from pornography and masturbation... as a test of self-control" or to 'quit' pornography all together if "excessive masturbation or pornography has become a problem" in their lives (No Fap n.d.). Across social media, they argue that pornography is a problem, citing Ted-X videos (such as Dines'), news articles, or books (again, such as Dines'), that inspired them to tackle their own problems. Frequently, they argue that their problem is the fault of the pornography industry and describe pornography-especially LGBTQ+ material—as a psychological and physiological drug.

The two most popular gateways into this community are Fight the New Drug (FTND; https://fightthenewdrug.org) and Your Brain On Porn (YBP; https://www.yourbrainonporn.com). FTND, which owns and operates NoFap.com, claims to be non-religious but was founded by an allMormon team and is supported by donations in excess of a million dollars annually from the Church of Jesus Christ of Latter-day Saints (Allen 2015; Hamblin 2016). YBP, the second gateway, claims on their website that "evolution has not prepared your brain for today's Internet porn," that it causes PED (Porn-induced Erectile Dysfunction), and cites the work of Gary Wilson, an Oregon man with no scientific training or background, who has made a career peddling pseudoscience and speaking about pornography addiction (Ley 2016; 2018; Hickman et al. 2016; Hamblin 2016).

5 Dines book is used in many places, Metaxis is a typical example. 
FTND and YPB's websites websites look like well-funded Silicon Valley startups: they are clean, modern, obviously well-designed. NoFap invites visitors to 'Get A Grip On Life,' and Fight The New Drug has pictures of attractive race- and gender-diverse young adults. Both immediately dive into to "Peer-Reviewed Research On How Pornography Affects The Brain... Peer-Reviewed Research On How Pornography Affects The Heart... [and] Peer-Reviewed Research On How Pornography Affects The World" (National Center on Sexual Exploitation (NCOSE) n.d.). Each claim in these sections are backed up by references and links to articles. Anything more than a cursory examination, however, reveals that the groups are playing into the general public's perceived information illiteracy. The claims and studies cited are, more often than not, poorly designed, suspiciously funded, misleading, incorrectly derived, or just outright false (D. J. Ley 2018; Oeming 2018; Bradley et al. 2016; Mialon et al. 2012; Wéry et al. 2016; Wilt et al. 2016). The problems with the sources would be immediately clear to any librarian trained in resource evaluation: many of the referenced journals are suspiciously titled, no longer active, or were funded by the organizations mentioned in this article. These sites offer a valuable pedagogical example for instructional librarians and resource evaluators. Unfortunately, this is more than just intellectual dishonesty and manipulation. As David Ley and others point out, the claims on these websites and in these articles are exploitative, stigmatizing, marginalizing and "serve to justify current and future discriminatory behaviours which impede social justice and rely on gender or racial stereotypes" (D. J. Ley 2018, 210). The only consistent finding in the literature is that pornography is a mental health issue among individuals who have moral, religious, or social issues with pornography (D. J. Ley 2018).

Above, I suggested that these groups were adopting the method of climate change deniersgroups that are often funded by the corporations whose profits would be harmed from climate change legislation (Björnberg et al. 2017; Hansson 2017; Davenport and Lipton 2017; IPCC 2018; EarthTalk 2014; Norton 2016). The same perverse incentives apply here: internet filtering, moral panic, and censorship actually benefit these groups. The most obvious benefit is the purchase of 
books condemning the corrupting effects of pornography that are recommended at every turn.

These are largely written or published by a sprawling compendium of various religious groups. The Porn Myth, for example, was written by Catholic speaker and writer Matt Fradd and published by the Jesuit publisher Ignatius Press. Getting Off was written by 'radical Christian' Robert Jensen, a proponent of the theory that transgender 'ideology' and feminism endangers masculinity. There is, however, a much less obvious and far more profitable incentive for these companies: internet filtering software. This represents the third prong of the anti-sexuality movement: groups that downplay their religious connections (and millions of dollars of funding) while arguing that uncontrolled sexual representation is a moral and a societal hazard that leads to prostitution and sexual trafficking, along with the already-mentioned 'homosexuality' and 'transgenderism.' I will focus on the most significant of these groups and their campaign against libraries in the remainder of this article.

The National Center on Sexual Exploitation (NCOSE) was originally founded in 1962 as Morality in the Media, an anti-homosexual, anti-Hollywood, anti-birth control organization. They remained active under that name until the Bush presidency in the early aughts (Strub 2011). In 2015 the group rebranded, recalibrated its targets, and launched a new web presence designed to inspire activists nationally via the internet rather than the sustained and slow process of building small local efforts. Today, www.endsexualexploitation.org is designed to serve as a repository of information, offering handy guides on how to get local media attention and what terms should be searched in educational databases to find supposedly-inappropriate information. Each year, accompanied by pomp and circumstance, NCOSE presents an annual “Dirty Dozen List" of corporations or organizations for activists to target over the coming year. In the past, the list has included the U.S. Department of Justice for their "gross negligence" in not upholding federal obscenity laws (National Center on Sexual Exploitation (NCOSE) 2013d; 2019; 2019); Wikipedia, for "hous[ing] thousands of pornographic images"; Walmart (and others) for selling Cosmopolitan 
Magazine, which NCOSE sees as "verbally pornographic"; and a slew of major media corporations

(including Facebook, Twitter, Comcast, and HBO) for allowing sexual representation on their platforms (Watson 2019b; Locker 2018; National Center on Sexual Exploitation (NCOSE) 2013c;

2013d; 2013a; 2015b; 2017; 2019).

Until 2019, the Dirty Dozen list also regularly featured the American Library Association. NCOSE's crusade against the ALA is illustrative of their weaknesses as an organization. Beginning in 2013, they argued that

this self-styled champion of First Amendment freedoms has worked to encourage public libraries to keep their computer [sic] unfiltered. The ALA's misguided campaign has resulted in countless patrons of all ages being able to access or being inadvertently exposed to hardcore adult pornography and even child pornography on library computers (National Center on Sexual Exploitation (NCOSE) 2013b).

Over the course of the next few years the language became increasingly more righteous and angrier.

In the wake of a 2015 ALA press release stating their opposition to internet filtering, NCOSE

increased the pressure:

For years, American Library Association (ALA) has encouraged public libraries to keep all computers unfiltered and to allow patrons, including children, access to pornography. As a result, child sexual abuse, sexual assault, exhibitionism, stalking and other lewd behavior takes place in libraries across the country (National Center on Sexual Exploitation (NCOSE) 2015b).

Over the next two years, the rhetoric was stepped up even further: NCOSE called the ALA "zealous" and directly blamed them for a number of social ills: "[free internet access] has turned the once-safe community setting of the public library into a XXX space that fosters child sexual abuse, sexual assault, exhibitionism, stalking, and lewd behavior in libraries across the country" (National Center on Sexual Exploitation (NCOSE) 2017). Over the course of a half decade, NCOSE frequently argued that public libraries should install filtering software to limit the public's access to specific sites. In response, the ALA has repeatedly stated its opposition to filters, quoting from their Intellectual Freedom Manual, The Library Bill of Rights: 
1. "The use of Internet filters to block constitutionally protected speech, including content on social networking and gaming sites, compromises First Amendment freedoms and the core values of librarianship"

2. "Internet safety for children and adults is best addressed through educational programs that teach people how to find and evaluate information."

3. In the event that a filter is mandated, that "libraries and schools that choose to use content filters should implement policies and procedures that mitigate the negative effects of filtering to the greatest extent possible" (American Library Association 2006).

Additionally, the ALA has repeatedly published and publicized research showing the ineffectiveness of filters (Batch 2014; American Library Association 2006).

NCOSE and similarly-allied groups, however, are not necessarily arguing in good faith. Focusing on NCOSE alone, their blogs and news posts inevitably link to their "Tech Solutions" page where, at the top is a recommendation for Covenant Eyes, a self-installed internet filter that reports users' access to pornographic websites to their friends and family (National Center on Sexual Exploitation (NCOSE) 2015a). The company is owned by Ron DeHaas, a member of NCOSE's board who has argued that pornography is sent by Satan (National Center on Sexual Exploitation (NCOSE) n.d.; DeHaas 2008). Other solutions include: NetNanny, whose CEO, Russ Warner, also contributes to NCOSE; CYBERsitter, whose CEO, Steve Ensley, contributes to both NCOSE and Enough is Enough, another anti-porn evangelical site (National Center on Sexual Exploitation 2017). Nearly every organization mentioned in this article sells expensive filtering software, or-in the case of Culture Reframed-self-help programs.

\section{Conclusion}

There will undoubtedly be further encroachments on intellectual freedom online-the effects of the aforementioned FOSTA/SESTA laws are becomingly increasingly evident, most notably in the banning of adult content from Tumblr in December of 2018. This article has provided the most current overview of the antisexuality movement to date. By examining their histories, motivations, and finances, I have demonstrated the interconnectedness and political nature of these 
superficially-secular groups. Throughout this article I have attempted to offer advice relevant to public and academic librarians.

Over the course of the literature review preformed for this article, the author noted a number of strategies adopted by local librarians and their allies:

- Recognize that these organizations are heavily nationally-focused, and that they have not participated in on-the-ground local organizing. On the whole, librarians exist in local communities and should cultivate networks of allies and advocates that they can draw upon.

- Understand that organizations like NCOSE offer activist strategies on how to discover what they see as controversial material and prepare contingency plans.

- Citations about sexuality and pornography that make large arguments should evaluated with a critical eye. It may be worth reaching out to local academics or experts for support.

- Prepare material on the disadvantages and dangers of filtering software and technologies and how they may be harmful for library patrons or outside interest groups that suggest filtering,. Draw attention to the fact that internet filters disproportionately hurt minoritized groups.

- Draw upon resources such as ALA's Intellectual Freedom Manual Library and Library Juice Press' Handbook of Intellectual Freedom.

- Rely on local media outlets or social media networks to draw attention towards censorship attempts and the pitfalls of filtering technologies.

- If a filter is locally mandated, advocate for technologies or companies not linked to religious or anti-LBGTQ+ groups.

In conclusion, it is worth noting that these groups are not just targeting outright pornography: their "proof" pages include LGBT+ content, sexual education material, body positivity information, sex 
worker resources, birth control information, and political activism. Pornography is just the first step.

\section{References:}

Allen, Samantha. 2015. “'Porn Kills Love': Mormons' Anti-Smut Crusade,” The Daily Beast. October 20, 2015. https://www.thedailybeast.com/articles/2015/10/20/porn-kills-love-mormonsanti-smut-crusade.

American Library Association. 2006. "Filters and Filtering." Text. Advocacy, Legislation \& Issues. July 24, 2006. http://www.ala.org/advocacy/intfreedom/filtering.

- - - 2013. "Number of Challenges by Reasons, Initiator, \& Institution, 1990-99." Banned and Challenged Books. American Library Association. September 6, 2013. http://www.ala.org/advocacy/bbooks/frequentlychallengedbooks/statistics/1990-99.

Arnold, Amanda. 2017. "The War on Porn Is Back." Jezebel. September 20, 2017. https://jezebel.com/the-war-on-porn-is-back-1810469452.

Baillie, Ann M. 2017. "Protection Versus First Amendment Violation: Self-Censorship as It Relates to Youth and Young Adult Services." SLIS Connecting 6 (2): 16-27. https://doi.org/10/ggbthh.

Baker, Ben. 2020. To Repeal Section 181.060, RSMo, and to Enact in Lieu Thereof Two New Sections Relating to Parental Oversight of Public Libraries, with Penalty Provisions. Revised Statutes of Missouri. Vol. 181. https://house.mo.gov/billtracking/bills201/hlrbillspdf/4634H.01I.pdf.

Barack, Lauren. 2016. "Banning the Ban On LGBTQ Filters in Libraries." School Library Journal. October 26, 2016. https://www.slj.com?detailStory=banning-the-ban-on-lgbtq-filters-inlibraries.

Barnett, Jerry. 2016. Porn Panic!: Sex and Censorship in the UK. John Hunt Publishing.

Batch, Kristen R. 2014. “Fencing Out Knowledge: Impacts of the Children's Internet Protection Act 10 Years Later.” Policy Brief. Chicago, IL: American Library Association. http://www.ala.org/advocacy/sites/ala.org.advocacy/files/content/intfreedom/censorshi pfirstamendmentissues/FINALCIPA_Report.pdf.

Björnberg, Karin Edvardsson, Mikael Karlsson, Michael Gilek, and Sven Ove Hansson. 2017. "Climate and Environmental Science Denial: A Review of the Scientific Literature Published in 19902015." Journal of Cleaner Production 167 (November): 229-41. https://doi.org/10/gbvtwv.

Boulton, Christopher. 2015. "Antiporn Agendas: Feminism, Internet Filtering, and Religious Strategies." In New Views on Pornography: Sexuality, Politics, and the Law, edited by Lynn Comella and Shira Tarrant, 77-96. Santa Barbara: ABC-CLIO.

Bradley, David F., Joshua B. Grubbs, Alex Uzdavines, Julie J. Exline, and Kenneth I. Pargament. 2016. "Perceived Addiction to Internet Pornography among Religious Believers and Nonbelievers." Sexual Addiction \& Compulsivity 23 (2-3): 225-43. https://doi.org/10/gfxcbq.

Bronstein, Carolyn. 2011. Battling Pornography: The American Feminist Anti-Pornography Movement, 1976-1986. Cambridge ; New York: Cambridge University Press.

Bronstein, Carolyn, and Whitney Strub, eds. 2016. Porno Chic and the Sex Wars: American Sexual Representation in the 1970s. Amherst: University of Massachusetts Press.

CAF America. 2017. "IRS Form 990 - Charities and Foundation America." Foundation Search. http://www.foundationsearch.com/990/LATEST/4/CHARITIES\%20AID\%20FOUNDATION \%20AMERICA\%202017\%20431634280.PDF. 
Chu, Andrea Long. 2018. “'Pornographic Spectatorship, or, Did Sissy Porn Make Me Trans?'” In Author Distributed. UCLA. https://static1.squarespace.com/static/5a9b1c0812b13f48e686fdc4/t/5a9c17e1f9619a44 9856c4fe/1520179170246/Chu-Did+Sissy+Porn+Make+Me+Trans\%3F+\%28QD2\%29.pdf.

Coaston, Jane. 2019. “There's a Conservative Civil War Raging — over Porn.” Vox. December 12, 2019. https://www.vox.com/policy-and-politics/2019/12/12/21003109/pornographyobscenity-barr-doj-conservatives-libertarians.

Culture Reframed. 2018. "Culture Reframed Calls on Corporations Nationwide to Install Curbs on Porn." Culture Reframed (blog). December 4, 2018. https://www.culturereframed.org/culture-reframed-calls-on-corporations-nationwide-toinstall-curbs-on-porn/.

Davenport, Coral, and Eric Lipton. 2017. "How G.O.P. Leaders Came to View Climate Change as Fake Science.” The New York Times, June 3, 2017, sec. U.S. https://www.nytimes.com/2017/06/03/us/politics/republican-leaders-climatechange.html.

Dawkins, April M. 2018. "The Decision by School Librarians to Self-Censor: The Impact of Perceived Administrative Discomfort." Teacher Librarian 45 (3): 8-12.

DeHaas, Ron. 2008. "The Perfect Sin." Covenant Eyes (blog). January 17, 2008. https://www.covenanteyes.com/2008/01/17/the-perfect-sin/.

EarthTalk. 2014. "How Does Climate Denial Persist?" Scientific American. December 22, 2014. https://www.scientificamerican.com/article/how-does-climate-denial-persist/.

Flood, Alison. 2015. "Are Americans Falling in Love with Censorship?” The Guardian, August 7 , 2015, sec. Books. https://www.theguardian.com/books/2015/aug/07/are-americansfalling-in-love-with-censorship.

- - - 2020. "Missouri Could Jail Librarians for Lending 'age-Inappropriate' Books." The Guardian, January 16, 2020, sec. Books. https://www.theguardian.com/books/2020/jan/16/missouri-could-jail-librarians-forlending-age-inappropriate-books-parental-oversight-of-public-libraries-bill.

Gayle, Damien. 2016. "UK to Censor Online Videos of 'non-Conventional' Sex Acts." The Guardian, November 23, 2016, sec. Technology. https://www.theguardian.com/technology/2016/nov/23/censor-non-conventional-sexacts-online-internet-pornography.

Hamblin, James. 2016. “How One State Declared Pornography a 'Public-Health Crisis.'” The Atlantic. April 14, 2016. https://www.theatlantic.com/health/archive/2016/04/a-crisis-ofeducation/478206/.

Hansson, Sven Ove. 2017. "Science Denial as a Form of Pseudoscience." Studies in History and Philosophy of Science Part A 63 (June): 39-47. https://doi.org/10/gbvxxp.

Hickman, Shannon, Kristin Marie Bennion, Natasha Helfer Parker, and Kristin Hodson. 2016. “OpEd: Utah Students Need Real Sex Ed, Not 'Fight the New Drug."' The Salt Lake Tribune. October 2, 2016. https://archive.sltrib.com/article.php?id=4409139\&itype=CMSID.

Holley, Robert P. 2014. "Sex and Intellectual Freedom.” In The Library Juice Press Handbook of Intellectual Freedom: Concepts, Cases, and Theories, edited by Mark Alfino and Laura Koltutsky, 21. Sacramento, CA: Library Juice Press. Available at: htp://digitalcommons.wayne.edu/slisfrp/122.

IPCC. 2018. "Global Warming of $1.5^{\circ} \mathrm{C}$. An IPCC Special Report on the Impacts of Global Warming of $1.5^{\circ} \mathrm{C}$ above Pre-Industrial Levels and Related Global Greenhouse Gas Emission Pathways, in the Context of Strengthening the Global Response to the Threat of Climate Change, Sustainable Development, and Efforts to Eradicate Poverty." IPCC. https://www.ipcc.ch/sr15/. 
Jackman, Myles. 2018. "Pornography Is the Canary in the Coalmine of Free Speech." Obscenity Law. May 20, 2018. http://mylesjackman.com/index.php/my-blog/107-pornography-is-thecanary-in-the-coalmine-of-free-speech.

Jacobson, Linda. 2016. “Unnatural Selection: More Librarians Are Self-Censoring." School Library Journal, September. https://www.slj.com?detailStory=unnatural-selection-more-librariansself-censoring.

Jamison, Andrea. 2018. "Librarians Beware: Self-Censorship." Intellectual Freedom Blog (blog). May 8, 2018. https://www.oif.ala.org/oif/?p=13550.

Jewish Community Foundation Of The Jewish Federation Council Of Greater Los Angeles. 2017. "IRS Form 990 - Jewish Community Foundation." Foundation Search. http://www.foundationsearch.com/990/LATEST/9/JEWISH\%20COMMUNITY\%20FOUD\% 200F\%20THE\%20JEWISH\%20FED\%20COUN\%200F\%20GREATER\%20L\%20A\%202016 $\% 20956111928 . P D F$.

Knibbs, Kate. 2015. “Selling Erotic Ebooks Is Illegal in Germany Before 10pm.” Gizmodo. June 22, 2015. https://gizmodo.com/selling-erotic-ebooks-is-illegal-in-germany-before-10pm1713112318.

LaRue, James. 2018. "Education Is Not Pornography." Intellectual Freedom Blog (blog). October 12, 2018. https://www.oif.ala.org/oif/?p=16002.

Ley, David. 2016. "Your Brain on Porn: It's Not Addictive." Psychology Today. June 25, 2016. http://www.psychologytoday.com/blog/women-who-stray/201307/your-brain-porn-itsnot-addictive.

Ley, David J. 2018. “The Pseudoscience behind Public Health Crisis Legislation.” Porn Studies 5 (2): 208-12. https://doi.org/10/gft4cj.

Liam, Jason. 2017. “Age 22 - I Genuinely Thought I Could Have Been Transgender (Autogynephilia). If You Saw Me Today, You Wouldn't Believe I Was That Person.” Your Brain On Porn (blog). June 7, 2017. https://www.yourbrainonporn.com/rebooting-accounts/rebooting-accountspage-1/age-22-i-genuinely-thought-i-could-have-been-transgender-autogynephilia-if-yousaw-me-today-you-wouldnt-believe-i-was-that-person/.

Locker, Melissa. 2018. "Walmart and Cosmo: 9 Things to Know about the Anti-Porn Group Claiming Victory." Fast Company. March 28, 2018. https://www.fastcompany.com/40550889/walmart-and-cosmo-9-things-to-know-aboutthe-anti-porn-group-claiming-victory.

Metaxis, Eric. 2016. "Pornography: Media Finally Waking up to What Christians Have Warned about for Years.” ChristianHeadlines.Com. April 20, 2016.

https://www.christianheadlines.com/columnists/breakpoint/pornography-the-media-isfinally-waking-up-to-what-christians-have-warned-about-for-years.html.

Mialon, Anaïs, André Berchtold, Pierre-André Michaud, Gerhard Gmel, and Joan-Carles Suris. 2012. "Sexual Dysfunctions Among Young Men: Prevalence and Associated Factors." Journal of Adolescent Health 51 (1): 25-31. https://doi.org/10/f34m5q.

Mower, Allyson. 2018. "Utah Education Network Reinstates Access to EBSCO Database for Students Across Utah." Intellectual Freedom Blog (blog). October 25, 2018. https://www.oif.ala.org/oif/?p=16157.

Murray, Frederic. 2017. "Responding to Database Challenges." Intellectual Freedom Blog (blog). November 13, 2017. https://www.oif.ala.org/oif/?p=11496.

National Center on Sexual Exploitation. 2017. "IRS Form 990 - National Center on Sexual Exploitation." National Center on Sexual Exploitation. https://endsexualexploitation.org/wp-content/uploads/biz_FYE-2018-990_No-ScheduleB_PUBLIC.pdf.

National Center on Sexual Exploitation (NCOSE). 2013a. "2013 Dirty Dozen." National Center on Sexual Exploitation (blog). 2013. https://endsexualexploitation.org/dirtydozen-2013/. 
—_- 2013b. "2013 Dirty Dozen: American Library Association.” National Center on Sexual Exploitation (blog). 2013. https://endsexualexploitation.org/dd2013-american-libraryassociation/.

—-_. 2013c. "2013 Dirty Dozen: Cosmopolitan." National Center on Sexual Exploitation (blog). 2013. https://endsexualexploitation.org/dd2013-cosmopolitan/.

———. 2013d. "2013 Dirty Dozen: Department of Defense." National Center on Sexual Exploitation (blog). 2013. https://endsexualexploitation.org/dd2013-department-of-defense/.

——- 2015a. "Resources: Technology Solutions." National Center on Sexual Exploitation (blog). March 13, 2015. https://endsexualexploitation.org/filtering-software/.

—_- 2015b. "2015 Dirty Dozen: American Library Association.” March 19, 2015. https://web.archive.org/web/20150319221149/https://endsexualexploitation.org/ala/.

——_. 2017. "2017 Dirty Dozen: American Library Association." National Center on Sexual Exploitation (blog). 2017. https://endsexualexploitation.org/ala/.

———. 2019. "2019 Dirty Dozen List - The Watchlist: Department of Justice." National Center on Sexual Exploitation (blog). 2019. https://endsexualexploitation.org/doj/.

_- - n.d. "An Overview Of The Issue." Fight the New Drug (blog). Accessed March 10, 2019a. https://fightthenewdrug.org/overview/.

———. n.d. "Ron DeHaas." National Center on Sexual Exploitation (blog). Accessed March 22, 2019b. https://endsexualexploitation.org/people/ron-dehaas/.

No Fap. n.d. "NoFap® and FAQs.” Subreddit FAQ. Reddit.Com. Accessed November 21, 2017. https://www.reddit.com/r/NoFap/wiki/index.

Norton, Andrew. 2016. "Climate Denial and the Populist Right." International Institute for Environment and Development. November 15, 2016. https://www.iied.org/climate-denialpopulist-right.

Oeming, Madita. 2018. "A New Diagnosis for Old Fears? Pathologizing Porn in Contemporary US Discourse." Porn Studies 5 (2): 213-16. https://doi.org/10/gfxcbr.

Peck, Nicholeen. 2018. "Public Databases Destroying 'Safe Places' For Children." Teaching SelfGovernment. October 5, 2018. https://teachingselfgovernment.com/parenting-blog/publicdatabases-destroying-safe-places-children.

PEN America. 2020. "Proposed Book Banning Bill in Missouri Could Imprison Librarians." PEN America (blog). January 15, 2020. https://pen.org/press-release/proposed-book-banningbill-in-missouri-could-imprison-librarians/.

Rickman, Wendy. 2010. "A Study of Self-Censorship by School Librarians." School Library Research 13: $1-21$.

"R/NoFap." 2011. Subreddit. Reddit. June 20, 2011. https://www.reddit.com/r/NoFap/.

Roberts, Alyssa, Chris Jones, and Nadia Pflaum. 2018. "Beyond The Books: Utah Mom Finds Pornographic Pics on Utah Education Network Database.” KUTV, September 21, 2018. http://kutv.com/news/beyond-the-books/beyond-the-books-utah-mom-findspornographic-pics-on-utah-education-network-database.

SB0185: Cause of Action for Minors Injured by Pornography. 2017. Utah State Legislature. Vol. SB185. https://le.utah.gov/ 2017/bills/static/SB0185.html.

Seipel, Brooke. 2020. "Missouri Bill Proposes 'parental Library Review Boards' That Could Land Librarians in Jail." The Hill. January 15, 2020.

https://thehill.com/homenews/news/478518-missouri-bill-proposes-parental-libraryreview-boards-that-could-land.

Smith, Emily. 2018. "Sex Workers Are Canaries In The Free Speech Coal Mine.” BuzzFeed News. April 7, 2018. https://www.buzzfeednews.com/article/emilysmith/sex-workers-sestacensorship-free-speech. 
State of Minnesota. 2019. Obscene Materials and Performances; Distribution and Exhibition Prohibited; Penalty. Minnesota Statutes. Vol. 617.241. https://www.revisor.mn.gov/statutes/cite/617.241.

Strauss, Valerie. 2020. "Missouri Bill: New Parent Board Could Toss Any Public Library Book It Deems Sexually Inappropriate - and Librarians Could Be Jailed." Washington Post, January 15, 2020. https://www.washingtonpost.com/education/2020/01/15/missouri-bill-newparent-board-could-toss-any-public-library-book-it-deems-sexually-inappropriatelibrarians-could-be-jailed/.

Strub, Whitney. 2011. Perversion for Profit: The Politics of Pornography and the Rise of the New Right. New York: Columbia University Press.

The Simms/Mann Family Foundation. 2017. "IRS Form 990 - The Simms/Mann Family Foundation." Foundation Search. http://www.foundationsearch.com/990/LATEST/3/SIMMSMANN\%20FAMILY\%20FOUNDATION\%202016\%20311812498.PDF.

Tobar, Hector. 2013. "Is Book Banning Increasing in American Schools and Public Libraries?" Los Angeles Times, December 19, 2013. http://articles.latimes.com/2013/dec/19/entertainment/la-et-jc-new-report-suggestsincrease-in-book-challenges-20131219.

Watson, Brian. 2019a. “FOSTA/SESTA and Libraries.” Hack Library School (blog). January 16, 2019. https://hacklibraryschool.com/2019/01/16/fosta-sesta-and-libraries/.

———. 2019b. "NCOSE's Dirty Dozen Censorship." Intellectual Freedom Blog (blog). March 21, 2019. https://www.oif.ala.org/oif/?p=17203.

Wéry, Aline, Kim Vogelaere, Gaëlle Challet-Bouju, François-Xavier Poudat, Julie Caillon, Delphine Lever, Joël Billieux, and Marie Grall-Bronnec. 2016. "Characteristics of Self-Identified Sexual Addicts in a Behavioral Addiction Outpatient Clinic." Journal of Behavioral Addictions 5 (4): 623-30. https://doi.org/10/f9kfhj.

Wilt, Joshua A., Erin B. Cooper, Joshua B. Grubbs, Julie J. Exline, and Kenneth I. Pargament. 2016. "Associations of Perceived Addiction to Internet Pornography with Religious/Spiritual and Psychological Functioning." Sexual Addiction \& Compulsivity 23 (2-3): 260-78. https://doi.org/10/gfxcbs. 